\title{
Geotecnologia e Ecologia da Paisagem no Monitoramento da Fragmentação Florestal
}

\author{
Nathalia Suemi Saito ${ }^{1}$, Maurício Alves Moreira ${ }^{1}$, Alexandre Rosa dos Santos ${ }^{2}$, \\ Fernando Coelho Eugenio ${ }^{3}$, Álvaro Costa Figueiredo ${ }^{4}$ \\ ${ }^{1}$ Programa de Pós-graduação em Sensoriamento Remoto, Instituto Nacional de Pesquisas Espaciais - INPE, \\ São José dos Campos/SP, Brasil \\ ${ }^{2}$ Departamento de Ciências Florestais, Universidade Federal do Espírito Santo - UFES, Alegre/ES, Brasil \\ ${ }^{3}$ Departamento de Ciências Florestais e da Madeira, Universidade Federal do Espírito Santo - UFES, \\ Jerônimo Monteiro/ES, Brasil \\ ${ }^{4}$ Departamento de Geologia, Universidade Federal do Espírito Santo - UFES, Alegre/ES, Brasil
}

\begin{abstract}
RESUMO
Objetivou-se diagnosticar e analisar a conectividade estrutural da paisagem fragmentada no entorno da Unidade de Conservação Reserva Particular de Patrimônio Natural Cafundó, propondo a restauração por Corredores Ecológicos. O mapeamento do uso e cobertura da terra e dos índices de ecologia da paisagem possibilitou detectar, analisar e compreender a estrutura da paisagem. Esses índices foram obtidos por meio do software TerraView, dentro do plugin GeoDMA, para as 10 classes mapeadas. No período estudado (1970 e 2007) verificaram-se poucas mudanças no uso e ocupação da terra, predominando a matriz pastagem em ambas as datas. A delimitação do Corredor Ecológico pelo método Processo Hierárquico Analítico utilizou cada classe mapeada para definir o peso relativo de sua instalação. Os resultados demonstraram um aumento da fragmentação da paisagem, sendo possível delimitar um Corredor Ecológico de menor custo como alternativa para aumentar a conectividade entre Unidades de Conservação.
\end{abstract}

Palavras-chave: unidades de conservação, AHP, métricas da paisagem, corredores ecológicos.

\section{Landscape Geotechnology and Ecology in Monitoring Forest Fragmentation}

\begin{abstract}
This work aimed to diagnose and analyze the structural connectivity of fragmented landscape surrounding the Conservation Unit Private Reservation of Natural Patrimony Cafundó, proposing the restoration through Ecological Corridors. The mapping of land use and land cover, and landscape ecology indexes allowed detecting, analyzing and understanding the landscape structure. These indexes were calculated using the GeoDMA plugin for the 10 mapped classes. During the study period (1970 and 2007) there have been few changes in the land use and occupation, predominantly to pasture matrix on both dates. The delimitation of Ecological Corridor for the Analytical Hierarchy Process method used each mapped class to set the relative weight for installation. The results showed an increase in the landscape fragmentation allowing the definition of an Ecological Corridor of lower cost as an alternative to increase the connectivity among conservation units.
\end{abstract}

Keywords: conservation units, AHP, landscape metrics, ecological corridor. 


\section{INTRODUÇÃO}

A expansão das atividades antrópicas tem intensificado as pressões sobre áreas com vegetação natural que, normalmente, não resistem à rápida ampliação da fronteira agrícola e de projetos urbanos. Entretanto, as preocupações com a qualidade de vida e o balanço entre áreas vegetadas e áreas intensamente povoadas têm aumentado, o que contribui para a implementação das chamadas Unidades de Conservação (UCs) (Oliveira, 2000; Kurasz et al., 2008).

As UCs foram criadas para proteger e manter os remanescentes de ecossistemas naturais, a fim de reduzir a perda da biodiversidade e garantir sua manutenção em longo prazo. Atualmente, muitas UCs se encontram na forma de pequenos fragmentos isolados, exigindo um manejo na forma de uma rede de fragmentos, visando reduzir as pressões das atividades do entorno. Umas das técnicas utilizadas nas redes de fragmentos são os chamados Corredores Ecológicos (CEs), que têm obtido sucesso como instrumento de planejamento e gestão biorregional dos recursos naturais, conciliando conservação da biodiversidade com as demandas socioeconômicas (Lopes et al., 2011).

Além disso, segundo Viana \& Pinheiro (1998), a definição de estratégias para a conservação da biodiversidade deve ultrapassar os limites das UCs e considerar as características e o potencial de conservação dos fragmentos vizinhos. De acordo com Narumalani et al. (2004), uma forma de analisar o grau de fragmentação da paisagem é pelo uso dos indicadores quantitativos baseados nas propriedades e no arranjo espacial de fragmentos dentro da paisagem. Comentam ainda que medidas estruturais quantitativas podem ser usadas para se analisar testes padrões da paisagem e estudar o comportamento das métricas com o tempo.

Dessa forma objetivou-se com este trabalho obter um diagnóstico multitemporal e uma análise da conectividade estrutural da paisagem fragmentada do entorno da Reserva Particular do Patrimônio Nacional (RPPN) de Cafundó, visando a viabilidade da restauração por meio de corredores ecológicos em direção à Floresta Nacional (FLONA) de Pacotuba.

\section{METODOLOGIA DE TRABALHO}

A área-alvo desta pesquisa, onde está localizada a RPPN de Cafundó, foi reconhecida e inserida no cadastro de UCs pela Embrapa em 1998. Considerada a mais representativa da Mata Atlântica, protegendo uma grande diversidade de espécies, foi a primeira UC dessa categoria a ser criada no Estado do Espírito Santo (Pirovani et al., 2015). Seu entorno corresponde a uma área de aproximadamente $70 \mathrm{~km}^{2}$ e situa-se entre as coordenadas geográficas $20^{\circ} 42^{\prime} 0,1^{\prime \prime}$ a $20^{\circ} 44^{\prime} 5^{\prime \prime}$ de latitude sul e $41^{\circ} 12^{\prime} 17^{\prime \prime}$ a $41^{\circ} 14^{\prime} 36^{\prime \prime}$ de longitude oeste (Figura 1).

A sudeste da área de pesquisa está localizada a FLONA de Pacotuba, instituída por decreto-lei federal de 13 de dezembro de 2002, tendo como objetivos promover o manejo de uso múltiplo dos recursos naturais, manutenção e proteção dos recursos hídricos e da biodiversidade, recuperação de áreas degradadas, educação ambiental, bem como apoio ao desenvolvimento de métodos de exploração sustentáveis no uso dos recursos naturais das áreas limítrofes. Ambas as UCs citadas localizam-se no município de Cachoeiro de Itapemirim, Espírito Santo, Brasil.

O trabalho foi desenvolvido em três etapas: I - Mapeamento do uso e da cobertura da terra; II - Análise quantitativa da estrutura da paisagem; III - Conexão entre os fragmentos e as UCs por meio dos corredores ecológicos.

O mapeamento de uso e cobertura da terra foi obtido por fotointerpretação em tela, na escala padrão de 1:1.500, sobre aerofotos ortorretificadas e moisacadas, em duas datas. A primeira em 1970 (aerofotos cedidas pelo Instituto de Defesa Agropecuária e Florestal) e a segunda em 2007 (cedida pelo Instituto Estadual de Meio Ambiente).

As classes temáticas dos mapas de uso e cobertura da terra foram agrupadas segundo o IBGE (2006), sendo: 1 - Floresta; 2 - Café; 3 - Campo sujo; 4 - Pastagem; 5 - Solo exposto; 6 - Rocha; 7 - Agricultura; 8 - Edificação; 9 - Água; 10 - Urbanização.

As informações dos dois mapas de uso e cobertura da terra gerados foram analisadas de forma interdependente, visando determinar a estrutura da paisagem nas duas datas estudadas. Além disso, realizou-se um cruzamento desses dois mapas para detecção da mudança ocorrida ao longo dos 37 anos. 


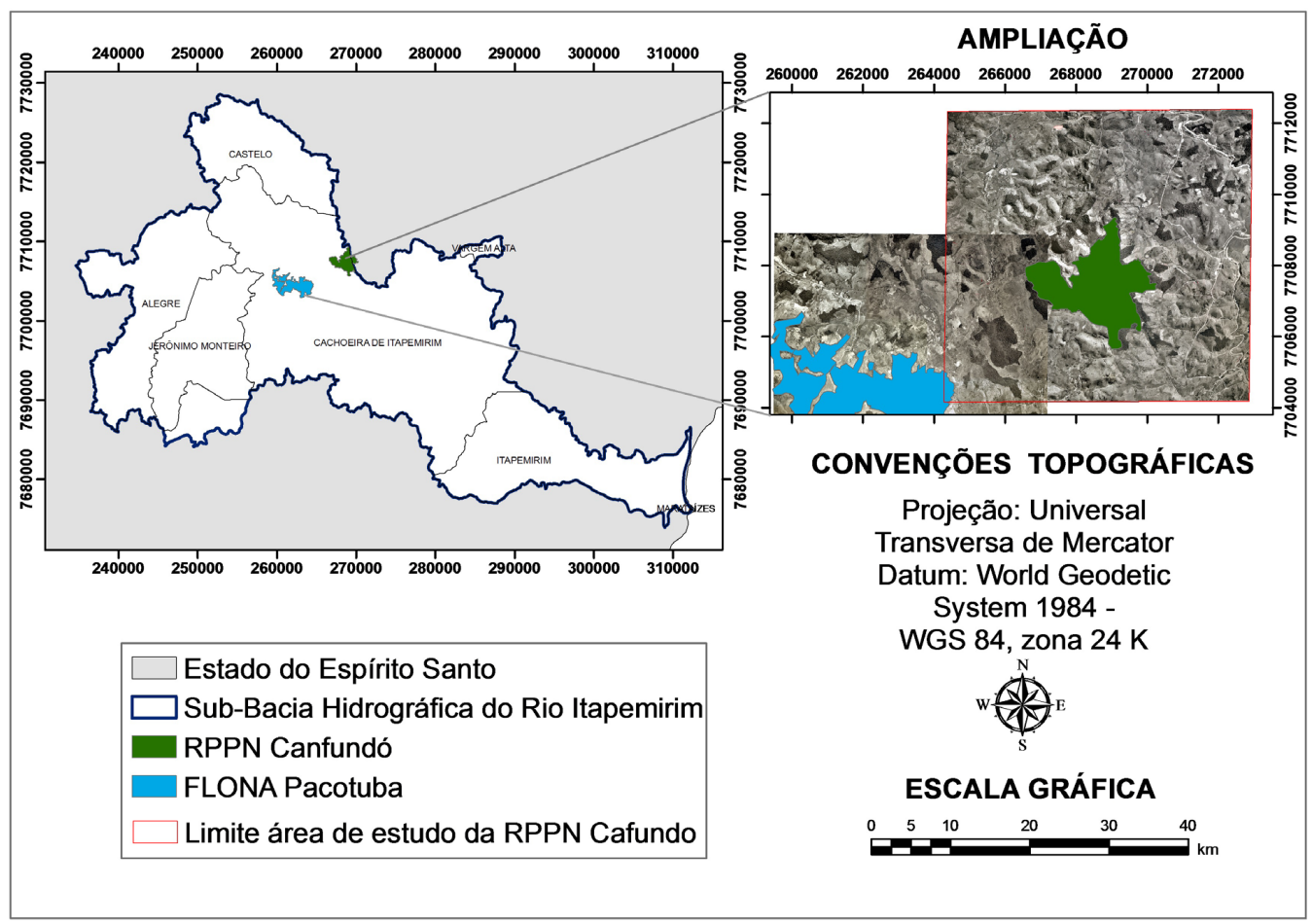

Figura 1. Localização da área de estudo.

Figure 1. Location of the study area.

As métricas utilizadas foram: número de polígonos (NP), perímetro, relação perímetro/área, índice de forma e distância média dos fragmentos à UC.

A descrição quantitativa da estrutura da paisagem na RPPN de Cafundó e de seu entorno foi realizada com o software TerraView versão 4.0 (Mcgarigal \& Marks, 1995), com o plugin GeoDMA, tendo por base os mapas temáticos de cobertura da terra descritos acima. As métricas utilizadas basearam-se na metodologia de Ribeiro et al. (2009) adaptada.

Para a seleção de áreas potenciais para restauração e realização da conexão entre os fragmentos e a UC por meio dos corredores ecológicos utilizou-se o método de suporte a decisão Processo Hierárquico Analítico (Analytical Hierarquical Process - AHP, em inglês) desenvolvido por Saaty (1977), definindo-se o peso relativo de cada classe de cobertura em termos da facilidade para a instalação dos CEs. Esse método foi implementada no software ArcGIS 9.3, o qual, ao contrário de outros softwares, não possui número limitante de classes a serem pareadas. A definição dos $\mathrm{CEs}$ foi realizada somente sobre a imagem mais recente, ou seja, de 2007. Essa técnica pareia as classes dentro de uma escala de importância relativa que varia de 1/9 (fator extremamente menos importante), passa pelo 1 (fator de igual importância) a 9 (fator extremamente mais importante).

A avaliação dos pesos calculados é realizada por meio da razão de consistência (RC), que deve ser menor que 0,10, conforme Saaty (1977). Esse método gera custos referentes a cada classe, que precisaram ser normalizados e considerados na definição dos CEs.

Após a aplicação do método AHP e geração dos pesos e custos normalizados, gerou-se possível CE interligando os fragmentos da UC Cafundó e da FLONA de Pacotuba, visando a viabilidade de restaurar o caminho entre esses pontos.

Para definição dos CE utilizou-se o software ArcGIS 9.3, definindo-se uma largura de $10 \%$ do comprimento total, ou uma largura mínima de $100 \mathrm{~m}$, como indica a Resolução CONAMA n. 09/1996. Definidos os principais CEs, buscou-se saber quais os conflitos no uso da terra (Brasil, 1996). 


\section{RESULTADOS E DISCUSSÃO}

Conforme a metodologia proposta, a área da RPPN de Cafundó e de seu entorno sofreram, ao longo dos 37 anos, algumas alterações, como se pode observar na Figura 2 e Tabelas 1 e 2.

Observa-se que a matriz da paisagem foi constituída pela pastagem em ambas as datas analisadas. A pastagem, quando bem manejada, proporciona maior proteção ao ambiente por conferir cobertura vegetal ao solo durante todo o ano, diferentemente das áreas agrícolas, que expõem os solos durante o seu preparo (Pinto et al., 2005). Entretanto, Trabaquini (2013), em seus estudos em áreas agrícolas no Mato Grosso, constatou que as propriedades físicas e químicas do solo se deterioram com o tempo de uso agrícola.

Houve um aumento significativo do NP total, de 704, em 1970, para 1.264, em 2007, e redução do tamanho médio das manchas e de sua área total. Esse resultado aponta para um possível processo de fragmentação da paisagem, principalmente da classe floresta, uma vez que essa classe teve um aumento do NP de 110 para 194 entre os anos de 1970 e 2007, respectivamente, com redução da área média dos fragmentos (Tabelas 1 e 2).

Uma análise isolada do índice NP da classe floresta é insuficiente para informar a existência de fragmentação da área. Verificou-se que os novos polígonos dessa classe não foram resultantes da implantação de novas áreas de floresta, ou seja, o aumento do NP ocorreu sobre áreas preexistentes de floresta, a qual cedeu áreas para outras classes.

Além disso, a fragmentação fica mais evidente ao se analisar as métricas de perímetro/área e índice de forma. Essas auxiliam na compreensão da forma dos fragmentos, sendo que quanto mais regulares menos sofrerão pressão de borda, estando menos susceptíveis a novas fragmentações.

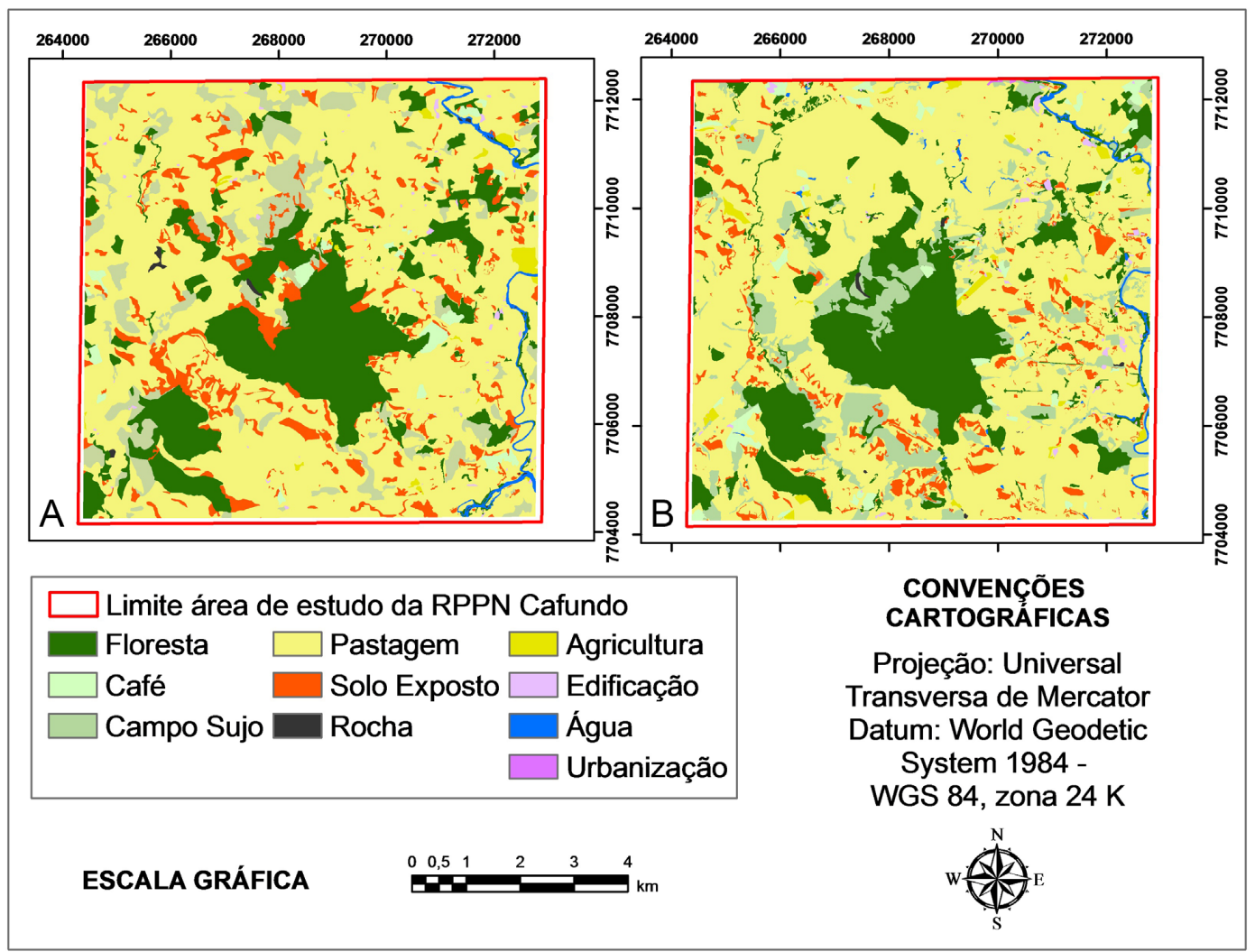

Figura 2. Uso e cobertura da terra para a área de estudo em 1970 (A) e em 2007 (B).

Figure 2. The use and land cover for the study area in 1970 (A) and 2007 (B). 
Tabela 1. Métricas da paisagem para a área de estudo em 1970.

Table 1. Landscape metrics for the study area in 1970.

\begin{tabular}{lccccc}
\multicolumn{1}{c}{ Classe } & NP & Area $\left(\mathbf{k m}^{2}\right)$ & Perímetro $\mathbf{( k m )}$ & Perímetro/área & Índice de forma \\
\hline Floresta & 110 & 13,0306 & 153,0969 & 0,0733 & 1,5364 \\
Café & 24 & 0,9263 & 21,5820 & 0,0565 & 1,2909 \\
Campo sujo & 83 & 6,0212 & 125,6746 & 0,0389 & 1,4880 \\
\hline Pastagem & 45 & 41,0777 & 437,9282 & 2,7759 & 1,9100 \\
\hline Solo exposto & 297 & 5,5899 & 223,7201 & 0,1191 & 1,5208 \\
\hline Rocha & 24 & 0,1132 & 6,4172 & 0,1857 & 1,2754 \\
\hline Agricultura & 23 & 0,4452 & 12,9001 & 0,2212 & 1,3584 \\
Edificação & 94 & 0,2291 & 18,8734 & 0,1374 & 1,1333 \\
\hline Água & 4 & 0,5420 & 31,5907 & 4,1506 & 4,6010 \\
\hline Total & 704 & 62,9273 & 839,6538 & & \\
\hline
\end{tabular}

NP: número de polígonos.

Tabela 2. Métricas da paisagem para a área de estudo em 2007.

Table 2. Landscape metrics for the study area in 2007.

\begin{tabular}{lccccc}
\multicolumn{1}{c}{ Classe } & NP & Area $\left(\mathbf{k m}^{2}\right)$ & Perímetro $\mathbf{( k m )}$ & Perímetro/área & Índice de forma \\
\hline Floresta & 194 & 12,9166 & 209,6453 & 0,9568 & 1,8250 \\
Café & 47 & 1,4132 & 38,5865 & 0,0652 & 1,3183 \\
Campo sujo & 179 & 6,4508 & 204,6055 & 0,1304 & 1,7696 \\
Pastagem & 63 & 42,5391 & 553,3686 & 1,3187 & 1,8350 \\
Solo exposto & 513 & 3,1014 & 211,6181 & 1,9175 & 1,7089 \\
Rocha & 13 & 0,0725 & 4,4480 & 0,1240 & 1,3421 \\
\hline Agricultura & 36 & 0,6143 & 22,8405 & 0,0651 & 1,3716 \\
\hline Edificação & 158 & 0,3411 & 26,7930 & 5,0334 & 1,1620 \\
\hline Água & 58 & 0,5661 & 38,8397 & 0,3633 & 1,4815 \\
Urbanização & 3 & 0,0223 & 1,6067 & 0,0749 & 1,5608 \\
\hline Total & $\mathbf{1 2 6 4}$ & $\mathbf{6 8 , 0 3 7 4}$ & $\mathbf{1 3 1 2 , 3 5 1 9}$ & & \\
\hline
\end{tabular}

NP: número de polígonos.

Para a relação perímetro/área, quanto mais próximo de 0 (zero) for o seu valor, mais regular é o fragmento, sendo que essa regularidade é alcançada para valores próximos de 1 para o índice de forma. Com isso, observou-se que todas as classes possuem polígonos mais irregulares no ano de 2007, quando comparados aos de 1970, exceto pastagem e agricultura (Tabelas 1 e 2).

A pastagem e a agricultura possuem regularidade dos polígonos, que relaciona-se com os plantios realizados em forma de talhões regulares, que facilitam a mecanização. Além disso, a pastagem compreende a matriz da paisagem, com cerca de $60 \%$ da área total, enquanto a agricultura representa cerda de $1 \%$ da área.

A fragmentação florestal no entorno da RPPN Cafundó pode estar interligada ao aumento das áreas de pastagem, cafezais e área agrícola.
Apesar da fragmentação florestal constatada no entorno da RPPN Cafundó de 1970 para 2007, observou-se que houve melhora das condições do ambiente pela diminuição da classe solo exposto. Essas áreas anteriormente propensas à degradação deram lugar a áreas de campo sujo, representando áreas em regeneração, e áreas agrícolas e de cafezal, cujas classes apresentaram pequeno aumento no NP. As novas áreas de campo sujo estão na proximidade da RPPN, auxiliando no processo de regeneração e expansão das áreas florestadas próximo à reserva (Figura 2) e na implantação de Corredores Ecológicos.

Devido à implantação de reservatórios e açudes na área do entorno da reserva houve um aumento da classe água.

Fazendo uma análise da distância média dos fragmentos em relação à reserva, essa aumentou de 
2,06 km, em 1970, para 2,12 km, em 2007. Isso pode indicar um avanço da fragmentação em direção às extremidades da área.

Após a análise geral da paisagem, pôde-se efetuar uma análise mais específica dos fragmentos florestais. Constatou-se que, assim como Ribeiro et al. (2009), a paisagem analisada encontra-se altamente fragmentada, com polígonos de pequena área. Entretanto, esses autores trabalharam com todo o Bioma Mata Atlântica do Brasil, considerando fragmentos entre 0 e 50 ha os menores.

A redução de um fragmento em fragmentos menores diminui as áreas centrais úteis e a qualidade do ambiente e aumenta os efeitos de borda (Ribeiro et al., 2009).

$\mathrm{Na}$ área de estudo do entorno da RPPN de Cafundó, entretanto, devido à pequena dimensão da área e dos fragmentos encontrados, consideraram-se classes de tamanho de polígonos muito reduzidos, enfatizando a fragmentação ocorrida.

Os fragmentos menores que 1 ha representavam cerca de $49 \%$ de todos os fragmentos de floresta em 1970 e cerca de 65\% em 2007 (Figura 3). A comparação com a porcentagem de área não será discutida, pois a grande dimensão da reserva distorce a comparação e distribuição dessas porcentagens na área. Mas vale ressaltar que em 1970 os remanescentes florestais ocupavam uma área de 13,0306 km² e, em 2007, de 12,9256 km².

A detecção de mudança foi realizada sobre a classe floresta (Figura 4 e Tabela 3), na qual observa-se que $8,43 \mathrm{~km}^{2}$ de florestas permaneceram inalteradas e que a classe responsável pelo maior desmatamento foi a
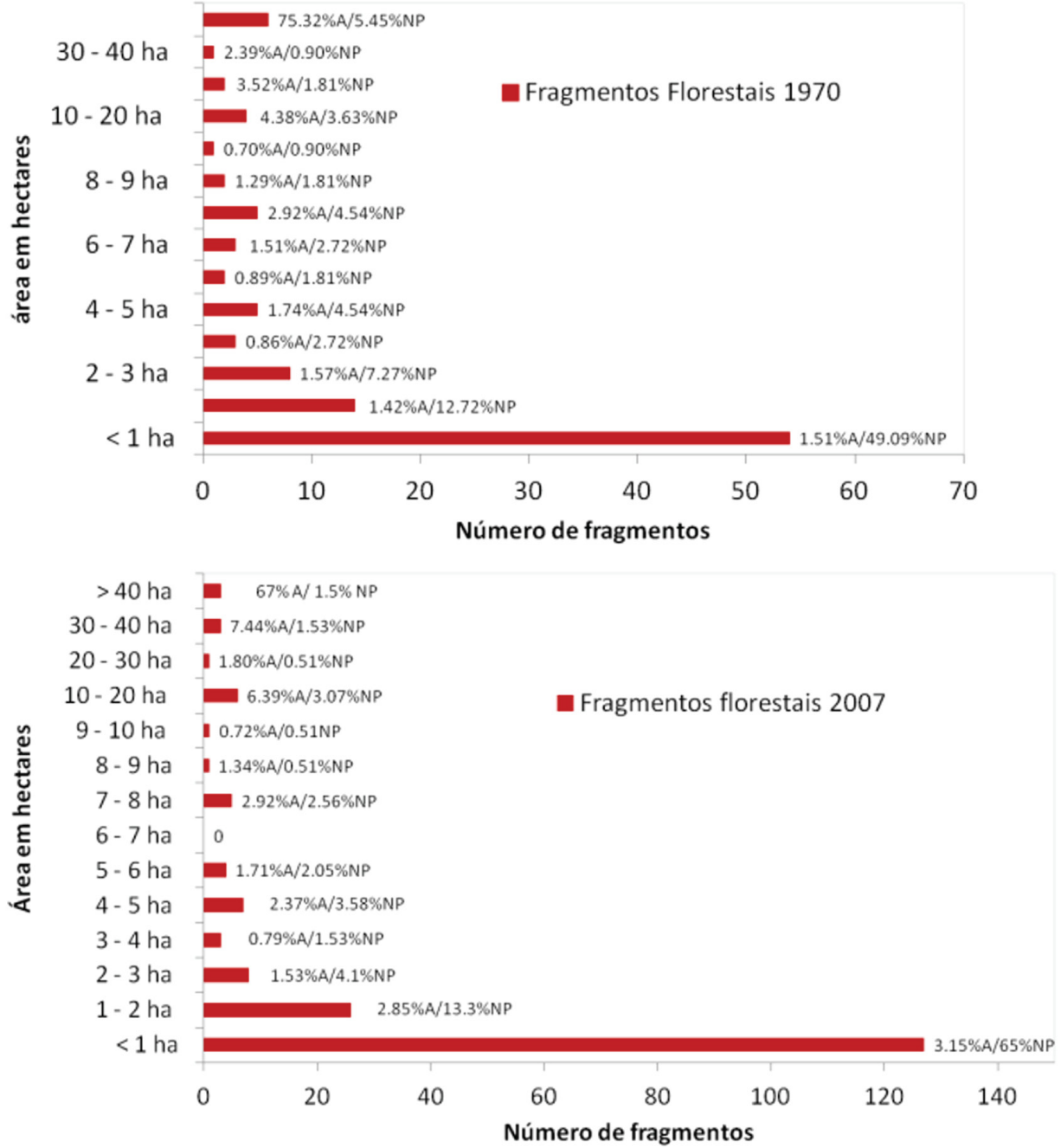

Figura 3. Distribuição dos fragmentos florestais por classes de área.

Figure 3. Distribution of forest fragments by area classes. 
pastagem. Diante disso, a classe pastagem não sofreu grandes variações em área na análise da mudança do uso floresta.

Como as análises estão espaçadas no tempo por um período de 37 anos, as mudanças não puderam ser detectadas de imediato. Entretanto, ao se investigar as áreas desmatadas observa-se que algumas áreas tornaram-se campo sujo em 2007. Esse resultado indica locais que sofreram retirada de floresta e que hoje já se encontram em recuperação, uma vez que campo sujo representa uma

Tabela 3. Área de mudança do uso e cobertura da terra sobre a classe floresta.

Table 3. Area-use change and land cover over the forest class.

\begin{tabular}{lccc} 
Classes & Desmatamento $\left(\mathbf{k m}^{2}\right)$ & Incremento $\left.\mathbf{( k m}^{2}\right)$ & $\begin{array}{c}\text { Diferença líquida }\left(\mathbf{k m}^{2}\right) \\
\text { (incremento - desmatamento) }\end{array}$ \\
\hline Café & 0,2346 & 0,1726 & $-0,062$ \\
\hline Campo sujo & 0,9796 & 0,7948 & $-0,1848$ \\
\hline Pastagem & 2,9760 & 2,6631 & $-0,3129$ \\
\hline Solo exposto & 0,2228 & 0,6835 & 0,4607 \\
\hline Rocha & 0,0163 & 0,0113 & $-0,005$ \\
\hline Agricultura & 0,0767 & 0,0357 & $-0,041$ \\
\hline Edificação & 0,0171 & 0,0250 & 0,0079 \\
Água & 0,0145 & 0,0350 & 0,0205 \\
Urbanização & 0 & 0 & 0 \\
Inalterado & 8,4346 & & \\
\hline
\end{tabular}

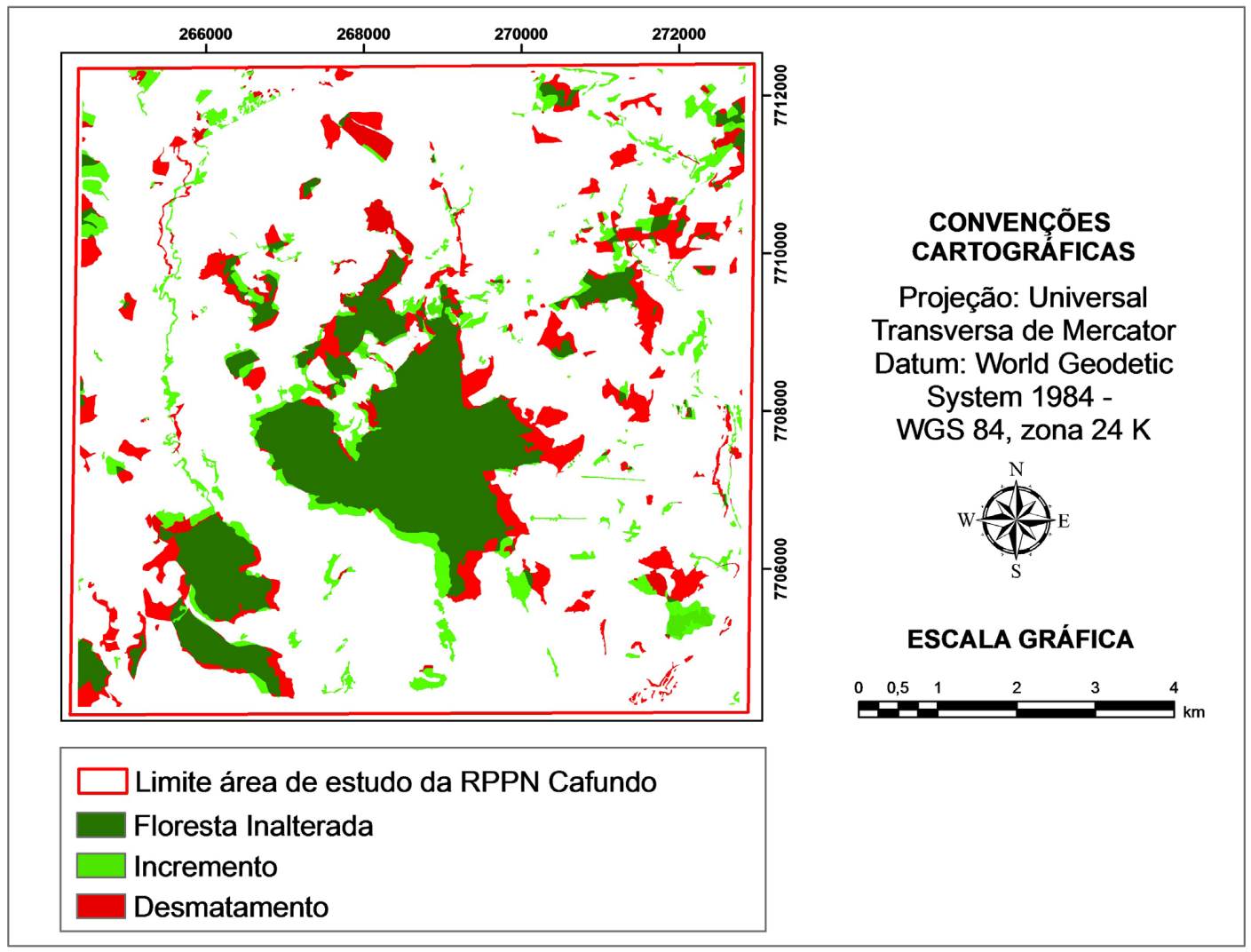

Figura 4. Mapa de detecção de mudança na classe floresta de 1970 para 2007.

Figure 4. Map of change detection in forest class, 1970 to 2007. 
etapa natural de regeneração do ambiente. Essa análise não considerou como incremento, pois a classe campo sujo vem de uma degradação da paisagem.

Observa-se que o segundo maior incremento de floresta ocorreu sobre a classe campo sujo, com um incremento de $0,79 \mathrm{~km}^{2}$, os quais completaram a regeneração detectada no mapeamento de 1970.

A última etapa do trabalho foi selecionar caminhos para a restauração da área em estudo, uma vez que a cobertura floresta representa cerca de $20 \%$ da área total e que, conforme Metzger (1998), quando esse limiar está abaixo de $30 \%$ deve-se restabelecer a conectividade da paisagem. Após a compreensão da estrutura da paisagem sugerida por esse autor foi então selecionado como ponto de partida a FLONA Pacotuba, com o intuito de se criar CE até a RPPN de Cafundó, interligando essas duas UCs. O corredor criado após aplicação do método AHP, com seus pesos e custos, pode ser visualizado na Figura 5.

Observa-se por meio do conflito de uso e cobertura da terra sob o corredor que a pastagem possui a maior concentração de área (Tabela 4). Esse resultado foi obtido devido ao peso atribuído a essa classe, cuja importância foi considerada fundamental, assim como determinado para a classe campo sujo, como pode ser observado nas matrizes de comparação pareada e de determinação dos pesos estatísticos de cada variável, nas Tabelas 5 e 6, respectivamente. Esse procedimento propiciou que a classe pastagem também fosse considerada adequada para integrar o CE, juntamente com campo sujo e floresta.

Tabela 4. Conflito de uso e cobertura da terra sob o corredor ecológico selecionado para a área de estudo. Table 4. Land use and land cover conflicts under ecological corridor selected for the study area.

\begin{tabular}{|c|c|}
\hline Classe & Área corredor $\left(\mathrm{km}^{2}\right)$ \\
\hline Floresta & 2,1797 \\
\hline Café & 0,2425 \\
\hline Campo sujo & 0,7196 \\
\hline Pastagem & 40,6186 \\
\hline Solo exposto & 0,1105 \\
\hline Rocha & 0 \\
\hline Agricultura & 0 \\
\hline Edificação & 0 \\
\hline Água & 0,0003 \\
\hline Urbanização & 0 \\
\hline Total & 43,87128 \\
\hline
\end{tabular}

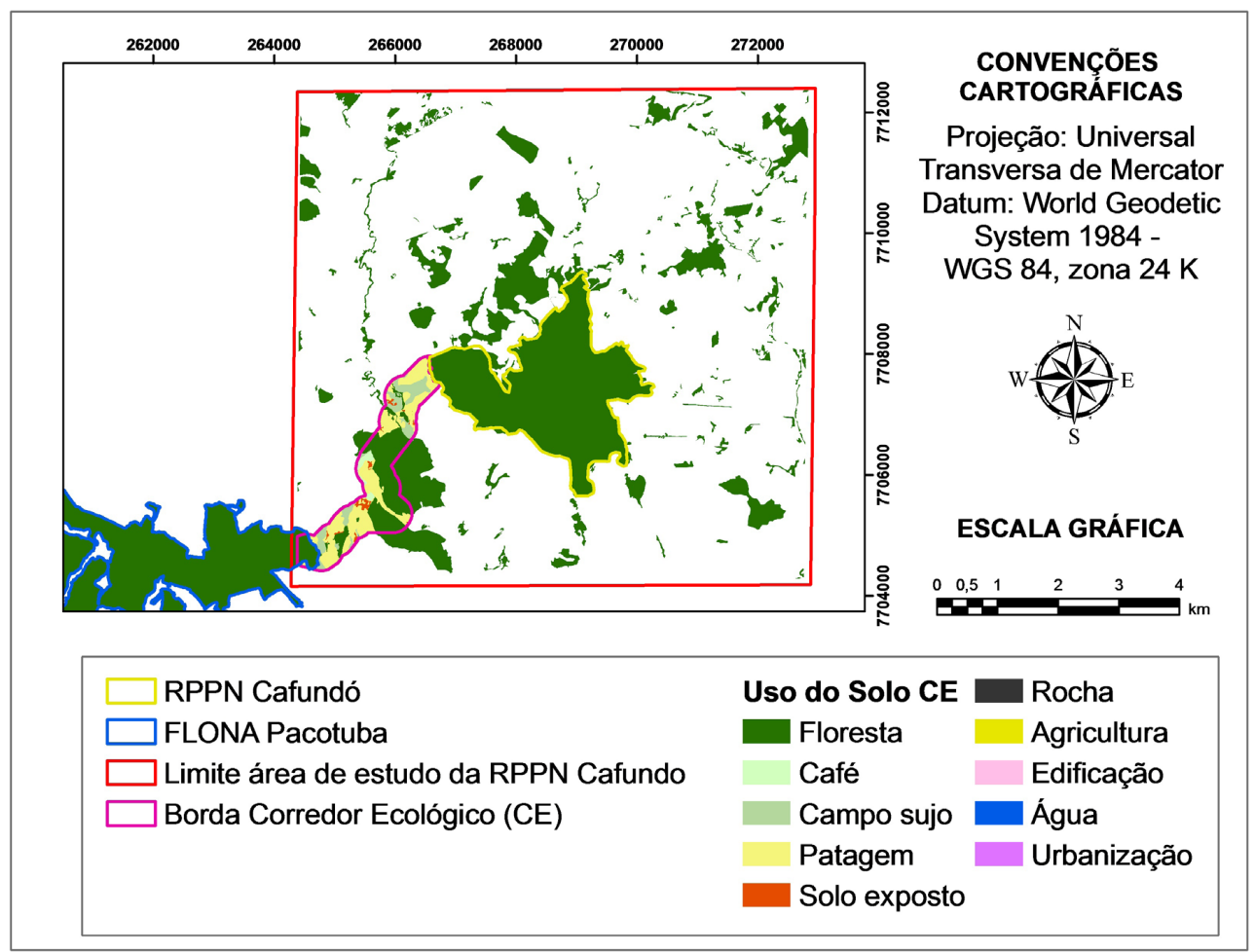

Figura 5. Corredores ecológicos selecionados para a restauração da área em estudo. Figure 5. Ecological corridors selected for restoration of the area under study. 
Tabela 5. Matriz de comparação pareada.

Table 5. Matrix of pairwise comparison.

\begin{tabular}{lccccccccccc}
\multicolumn{1}{c}{ Fatores } & Cafée & $\begin{array}{c}\text { Campo } \\
\text { sujo }\end{array}$ & Pastagem & $\begin{array}{c}\text { Solo } \\
\text { exposto }\end{array}$ & Rocha & Agricultura & Edificação & Água & Urbanização & Floresta \\
\hline Café & 1 & 0,17 & 0,20 & 0,33 & 0,33 & 0,33 & 0,50 & 0,50 & 0,50 & 0,11 \\
\hline Campo sujo & 6 & 1 & 3 & 7,14 & 9,01 & 3,03 & 9,01 & 9,01 & 9,01 & 0,14 \\
\hline Pastagem & 5 & 0,33 & 1 & 5 & 7,14 & 5 & 9,01 & 9,01 & 9,01 & 0,13 \\
\hline Solo exposto & 3 & 0,14 & 0,20 & 1 & 1 & 0,20 & 1 & 1 & 1 & 0,11 \\
\hline Rocha & 3 & 0,11 & 0,14 & 1 & 1 & 0,17 & 1 & 1 & 1 & 0,11 \\
\hline Agricultura & 3 & 0,33 & 0,20 & 5 & 6 & 1,00 & 7,14 & 7,14 & 7,14 & 0,13 \\
\hline Edificação & 2 & 0,11 & 0,11 & 1 & 1 & 0,14 & 1 & 1 & 1 & 0,11 \\
\hline Água & 2 & 0,11 & 0,11 & 1 & 1 & 0,14 & 1 & 1 & 1 & 0,11 \\
\hline Urbanização & 2 & 0,11 & 0,11 & 1 & 1 & 0,14 & 1 & 1 & 1 & 0,11 \\
\hline Floresta & 9 & 7 & 8 & 9 & 9 & 8 & 9 & 9 & 9 & 1 \\
\hline
\end{tabular}

Tabela 6. Determinação dos pesos estatísticos para cada variável.

Table 6. Determination of the statistical weights for each variable.

\begin{tabular}{llccccccccccc}
\multicolumn{1}{c}{ Fatores } & Café & $\begin{array}{c}\text { Campo } \\
\text { sujo }\end{array}$ & Pastagem & $\begin{array}{c}\text { Solo } \\
\text { exposto }\end{array}$ & Rocha & Agricultura & Edificação & Água & Urbanização & Floresta & Pesos \\
\hline Café & 0,03 & 0,02 & 0,02 & 0,01 & 0,01 & 0,02 & 0,01 & 0,01 & 0,01 & 0,05 & $\mathbf{0 , 1 9}$ \\
\hline Campo sujo & 0,17 & 0,11 & 0,23 & 0,23 & 0,25 & 0,17 & 0,23 & 0,23 & 0,23 & 0,07 & $\mathbf{1 , 8 9}$ \\
\hline Pastagem & 0,14 & 0,04 & 0,08 & 0,16 & 0,20 & 0,28 & 0,23 & 0,23 & 0,23 & 0,06 & $\mathbf{1 , 6 2}$ \\
\hline Solo exposto & 0,08 & 0,01 & 0,02 & 0,03 & 0,03 & 0,01 & 0,03 & 0,03 & 0,03 & 0,05 & $\mathbf{0 , 3 1}$ \\
\hline Rocha & 0,08 & 0,01 & 0,01 & 0,03 & 0,03 & 0,01 & 0,03 & 0,03 & 0,03 & 0,05 & $\mathbf{0 , 3 0}$ \\
\hline Agricultura & 0,08 & 0,04 & 0,02 & 0,16 & 0,16 & 0,06 & 0,18 & 0,18 & 0,18 & 0,06 & $\mathbf{1 , 1 1}$ \\
\hline Edificação & 0,06 & 0,01 & 0,01 & 0,03 & 0,03 & 0,01 & 0,03 & 0,03 & 0,03 & 0,05 & $\mathbf{0 , 2 7}$ \\
\hline Água & 0,06 & 0,01 & 0,01 & 0,03 & 0,03 & 0,01 & 0,03 & 0,03 & 0,03 & 0,05 & $\mathbf{0 , 2 7}$ \\
\hline Urbanização & 0,06 & 0,01 & 0,01 & 0,03 & 0,03 & 0,01 & 0,03 & 0,03 & 0,03 & 0,05 & $\mathbf{0 , 2 7}$ \\
\hline Floresta & 0,25 & 0,74 & 0,61 & 0,29 & 0,25 & 0,44 & 0,23 & 0,23 & 0,23 & 0,49 & $\mathbf{3 , 7 5}$ \\
\hline
\end{tabular}

Além disso, áreas que já possuíam fragmentos formam definidas como extremamente mais importantes (valor na escala de importância igual a 9) para minimizar os custos de implantação e aproveitá-las como stepping stones, acelerando o processo de restauração. Segundo Metzger (2000), os fragmentos circunvizinhos podem ajudar a controlar a diversidade de espécies tanto quanto a área do fragmento, se houver corredores ecológicos entre eles.

Além da dificuldade de definir CEs para a restauração do ambiente, outra dificuldade é a definição da largura do corredor. A largura encontrada no corredor atende ao especificado na resolução do CONAMA n. 09/1996, que fixa uma largura mínima para o corredor, que deve ser de 100 m (Brasil, 1996).

\section{CONCLUSÕES}

Após as análises propostas neste trabalho, percebeu-se que a área de estudo encontra-se, desde 1970, com transformações estruturais da paisagem e fragmentação das áreas de floresta. Apesar disso, novas áreas em regeneração mapeadas em 2007 contribuirão, futuramente, para a expansão das áreas florestadas da RPPN Cafundó. Outro aspecto relevante para a conservação da área foi a delimitação do corredor ecológico pelo método AHP, cujo resultado indicou a utilização de fragmentos preexistentes para auxiliar na conectividade da área.

O grande número de polígonos da classe pastagem e, principalmente, o crescimento das áreas agrícolas no entorno da reserva indicam a necessidade de políticas voltadas à restauração da área e a implantação de sistemas compatíveis para o desenvolvimento e conservação do entorno da RPPN Cafundó.

\section{STATUS DA SUBMISSÃO}

Recebido: 5 nov., 2014

Aceito: 9 jan., 2016 


\section{AUTOR(ES) PARA CORRESPONDÊNCIA}

\section{Fernando Coelho Eugenio}

Departamento de Ciências Florestais e da Madeira, Universidade Federal do Espírito Santo - UFES, Av. Governador Lindemberg, 316, CEP 29550-000, Jerônimo Monteiro, ES, Brasil e-mail: coelho.fernando@yahoo.com.br

\section{REFERÊNCIAS}

Brasil. Conselho Nacional do Meio Ambiente - CONAMA. Resolução n 9, de 24 de outubro de 1996. Estabelece corredor de vegetação área de trânsito a fauna. Diário Oficial da União [online], Brasília, DF (1996 nov.). [citado 2014 nov 5]. Disponível em: http://www.mma.gov.br/port/conama/ res/res02/res30302.html

Instituto Brasileiro de Geografia e Estatística - IBGE. Manual técnico de uso da terra. 2. ed. Rio de Janeiro: IBGE; 2006. Série Manuais Técnicos em Geociências n. 7.

Kurasz G, Rosot NC, Oliveira YMM, Rosot MAD. Caracterização do entorno da reserva florestal EMBRAPA/ EPAGRI de Caçador (SC) usando imagem Ikonos. Floresta 2008; 38(4): 641-649. http://dx.doi.org/10.5380/ rf.v38i4.13159.

Lopes NS, Moreau MS, Moraes MEB. Análise da paisagem com base na fragmentação: caso APA Pratigi, baixo Sul da Bahia, Brasil. Revista Eletrônica do Prodema 2011; 6(1): 53-67.

Mcgarigal K, Marks BJ. FRAGSTATS: spatial pattern analysis program for quantifying landscape structure. Portland: USDA Forest Service, Pacific Northwest Research Station; 1995. 122 p. General Technical Report PNW-GTR-351.

Metzger JP. Landscape ecology approach in the preservation and rehabilitation of riparian forest areas in S.E. Brazil. In: Chavéz S, Iddleton J, editores. Landscape ecology as a tool for sustainable development in Latin America. Logan: International Association for Landscape Ecology; 1998.
Metzger JP. Tree functional group richness and landscape structure in Brazilian tropical fragmented landscape. Ecological Applications 2000; 10(4): 1147-1161. http:// dx.doi.org/10.1890/1051-0761(2000)010[1147:TFGRA L]2.0.CO;2.

Narumalani S, Mishra DR, Rothwell RG. Change detection and landscape metrics for inferring anthropogenic processes in the greater EFMO area. Remote Sensing of Environment 2004; 91(3-4): 478-489. http://dx.doi. org/10.1016/j.rse.2004.04.008.

Oliveira YMM. Investigation of remote sensing for assessing and monitoring the araucaria forest of Brazil [tese]. Oxford: University of Oxford; 2000.

Pinto LVA, Ferreira E, Botelho SA, Davide AC. Caracterização física da bacia hidrográfica do ribeirão Santa Cruz, Lavras, MG e uso conflitante da terra em suas áreas de preservação permanente. Cerne 2005; 11(1): 49-60.

Pirovani DB, Silva AG, Santos AR. Análise da paisagem e mudanças no uso da terra no entorno da RPPN Cafundó, ES. Cerne 2015; 21(1): 27-35. http://dx.doi.org/10.1590/ 01047760201521011182 .

Ribeiro MC, Metzger JP, Martensen AC, Ponzoni FJ, Hirota MM. The Brazilian Atlantic Forest: How much is left, and how is the remaining forest distributed? Implications for conservation. Biological Conservation 2009; 142(6): 1141 1153. http://dx.doi.org/10.1016/j.biocon.2009.02.021.

Saaty LL. A scaling method for priorities in hierarchical structures. Journal of Mathematical Psychology 1977; 15(3): 234-281. http://dx.doi.org/10.1016/0022-2496(77)90033-5.

Trabaquini K. Sensoriamento remoto no estudo das relações entre tempo de uso agrícola dos solos e mudanças em suas propriedades físico-químicas no Cerrado matogrossense [tese]. São José dos Campos: Instituto Nacional de Pesquisas Espaciais; 2013.

Viana VM, Pinheiro LAFV. Conservação da biodiversidade em fragmentos florestais. Série Técnica IPEF 1998; 12(32): 25-42. 